\title{
Bachelor of Engineering
}

National Cancer Institute

\section{Source}

National Cancer Institute. Bachelor of Engineering. NCI Thesaurus. Code C71347.

A bachelor's degree in engineering awarded to a student after three, four or five years of studying engineering at an accredited university. It is a professional degree that involves a requirement for undertaking some engineering work. 